\title{
The position of the mental foramen in dentate and edentulous mandibles: clinical and surgical relevance
}

\author{
A. Charalampakis, G. Kourkoumelis, Ch. Psari, V. Antoniou, M. Piagkou, \\ T. Demesticha, E. Kotsiomitis, T. Troupis
}

Department of Anatomy, School of Medicine, Faculty of Health Sciences, National and Kapodistrian University of Athens, Greece

[Received: 11 March 2017; Accepted: 11 April 2017]

Background: The knowledge of the exact location of the mental foramen (MF) in dentate and edentulous mandibles is clinically important when constructing complete dentures, performing anaesthetic block of the lower-anterior teeth area and intervening in the MF nearby area. In edentulous mandibles, the bone resorption after teeth loss makes the mental nerve (MN) prone to damage due to the extreme location of the MF very close to the alveolar crest (AC). Chronic compression on the MN may result in pain in the area of $M N$ distribution (ipsilateral face and cheek area) and numbness at the lower lip. The purpose of the current study is to evaluate the exact position of the MF, calculating the distances MF-superior border of the AC and MF-inferior border of the mandible (IBM) in dentate and edentulous mandibles.

Materials and methods: One hundred and two (36 edentulous and 66 dentate) adult dry Greek mandibles were studied.

Results: In 9 out of 36 edentulous mandibles (25\%), the MF was found nearby the AC, while in 27 edentulous mandibles (75\%), the MF was located at an average distance $6.4 \mathrm{~mm}$ from the $A C$ and $12.6 \mathrm{~mm}$ from the IBM. In 38 out of 66 dentate mandibles (57.6\%), the MF was located at an average distance $13.6 \mathrm{~mm}$ from the $A C$ and $15.2 \mathrm{~mm}$ from the IBM. The dental status significantly affected ( $p=0.001)$ the distances MF-AC and MF-IBM. Side symmetry was observed for both dentate and edentulous mandibles ( $p=0.39$ and $p=0.45$ ).

Conclusions: The MF is an important landmark and its location needs to be considered prior to dental implants placement in order to avoid the MN injury and related complications. The position of MF is altered in edentulous mandibles compared with the dentate ones. The MF is a symmetric structure in Greeks. (Folia Morphol 2017; 76, 4: 709-714)

Key words: mental foramen, dentate, edentulous, mandible, bone resorption

Address for correspondence: T.G. Troupis, MD, PhD, Department of Anatomy, School of Medicine, Faculty of Health Sciences, National and Kapodistrian University of Athens, 75 Mikras Asias str., 11527 Athens, Greece, tel: +30-210-7462388, fax: +30-210-7462398, e-mail: ttroupis@gmail.com; troupis@med.uoa.gr 


\section{INTRODUCTION}

The mental foramen (MF) is located in the body of mandible midway between the inferior border of the mandible (IBM) and the alveolar crest (AC). The MF morphology, morphometry and location extensively studying in dry mandibles or by using radiographies $[1,3]$ were affected by the gender, the age and the race [40]. The MF also presents variability, as regards its form (single, double or triple) and shape (round, oblong, slit-like and irregular shape) [22], its bilateral location among the same and different populations and its unilateral location among different populations [11]. The MF location is an important factor when considering the mental and incisive anaesthetic block and surgeries in the outer premolar mandibular region [2]. Loss of teeth and their periodontal membranes result in alveolar bone resorption, and variable alterations in the mandible. The alveolar ridge resorption affects the height of the mandible and the foramina location. Initially, the resorption takes place on the AC, while the IBM remains unchanged [16]. The main reason for this phenomenon may be the function of the muscles of mastication [11]. The resorption process increases during the first year after teeth loss. Van Waas et al. [37] described an average bone loss ranging from $0.9 \mathrm{~mm}$ to $1.8 \mathrm{~mm}$ in mandibular canines' area and from $0.7 \mathrm{~mm}$ to $1.9 \mathrm{~mm}$ in the distal parts of the mandible. Bone resorption takes place within the first 2 years after teeth loss, and later bone loss gradually stabilised. The resorption process is faster in the labial and buccal parts of the $A C$ and is particularly increased in mandible than in maxilla [34]. The knowledge of the exact position of the MF is of paramount importance particularly in edentulous mandibles, due to the extreme location of the foramen nearby the $A C$ and the high risk of mental nerve (MN) injury, intraoperatively. This injury may cause transitory or permanent sensitive, thermal and tactile changes $[23,39]$. The MF location is directly affected by dental status. The morphology of edentulous mandibles increases the risk of intraoperative complications at the anterior mandible [19].

Taking into consideration the differentiation in foramen position in cases of edentulism, we designed to investigate in dry mandibles, the correlation between the dental status of the mandibles and the MF position, calculating the distance from the upper border of the MF, midline to the $A C$ and the distance from the lower border of the MF, midline to the IBM in dentate and edentulous dry mandibles in a Greek population.

\section{MATERIALS AND METHODS}

One hundred and two Greek adult dry mandibles (204 sides of observations) from the osseous collection of our Department were investigated for the location of the MF and possible presence of accessory MF. Mandibles of children, mandibles damaged, and bones with pathological conditions were excluded. In adults, the morphology of the mandible is mainly affected by the teeth presence or absence [19]. Considering this parameter, all mandibles were subdivided according to the dental status into dentate and edentulous mandibles. Sixty-six dentate mandibles with intact $A C$ and at least 14 teeth in the anterior area according to Amorim et al. [2] methodology and 36 edentulous mandibles with a variable degree of atrophy of the AC and no teeth in the anterior area were observed. The examined mandibles were placed on a standard basal plane searching the maximum contact surface when a vertical bilateral pressure was applied to the second molars' area. One investigator calculated the distance from the upper border of the MF midline to the upper border of the $\mathrm{AC}$ and the distance from the lower border of the MF midline to the IBM in dentate (Fig. 1A) and edentulous mandibles (Fig. 1B) by using a digital sliding calliper (Mitutoyo, with accuracy $0.01 \mathrm{~mm}$ ). All measurements performed by a single investigator, were taken twice and the average of two values was finally recorded.

\section{Statistical analysis}

Statistical analysis was performed and variables were expressed as mean and standard deviations (SD) for both sides. Statistical calculations were performed using the Statistical Package for the Social Sciences (SPSS) software version 21. The unpaired t-test was applied to detect the significant differences. One way ANOVA was performed to analyse the influence of the dental state on the measurements. Correlations between the MF and the side of occurrence were analysed using the Fisher's exact test. $P<0.05$ was considered as the level of statistical significance.

\section{RESULTS}

One hundred (98\%) mandibles presented at least one MF, while two (5.6\%) edentulous mandibles had a septum at their outer aperture of the MF, at the right side (Fig. 2A, B). The mean symphyseal height was $32.06 \mathrm{~mm}$ in dentate and $23.87 \mathrm{~mm}$ in edentulous mandibles. An extensive statistical analysis was per- 

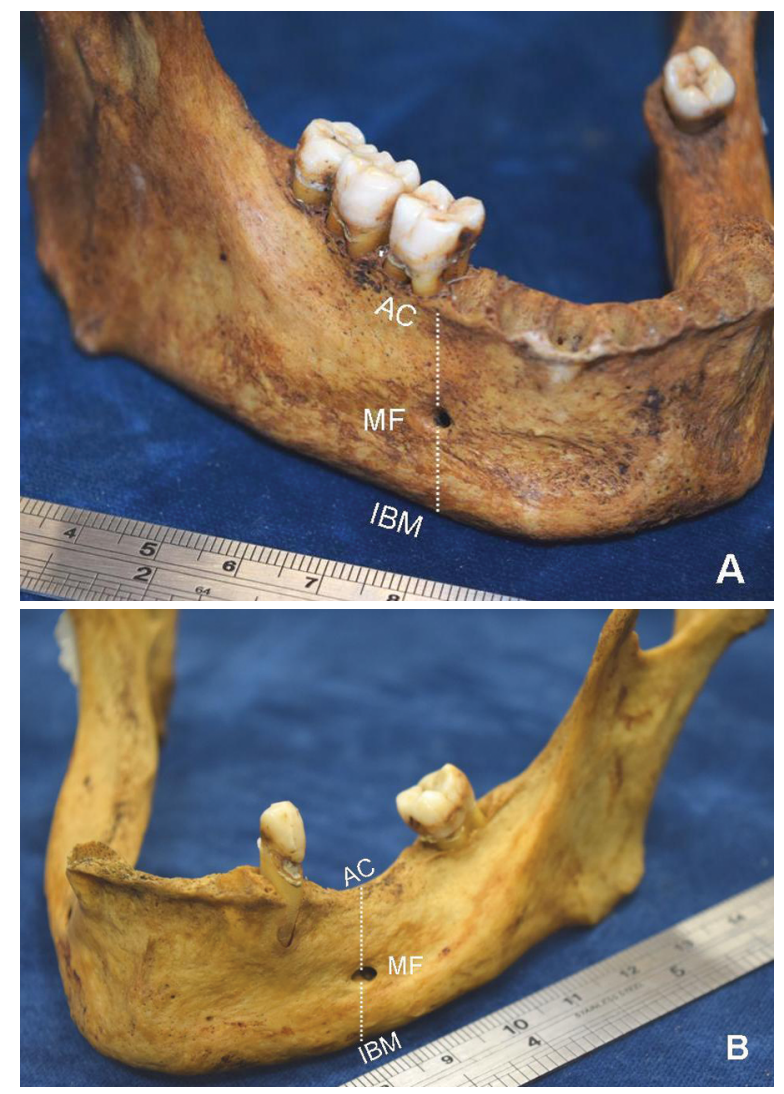

Figure 1. A. Calculation of the distance midline of the upper border of the mental foramen (MF) to the alveolar crest (AC) and the distance midline of the lower border of the MF to the inferior border of the mandible (IBM) in a dentate mandible; $\mathbf{B}$. Calculation of the distance midline of the upper border of the MF to the $A C$ and the distance midline of the lower border of the MF to the IBM in an edentulous mandible.

formed as regards the AC-MF and IBM-MF distances, separately for the dentate and edentulous mandibles. In edentulous mandibles, the MF was nearby the alveolar ridge with an incidence of $75 \%$ ( $27 / 36$ cases) at an average distance of $6.4 \mathrm{~mm}$ from the superior border of the AC and $12.6 \mathrm{~mm}$ from the IBM. The

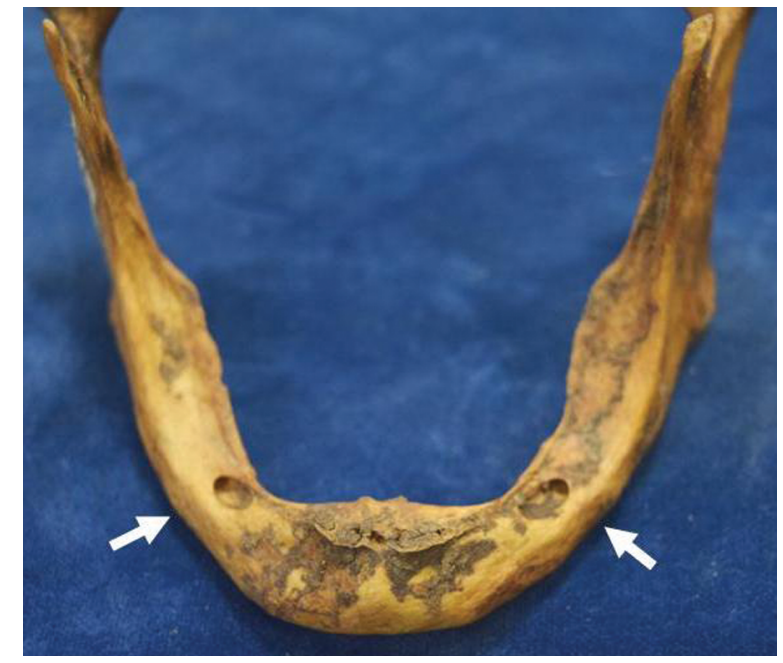

Figure 3. The white arrows indicate the extreme location of both mental foramina at the alveolar crest $(\mathrm{AC})$ due to the high degree of bone resorption (foramina transposition).

extreme positions of the MF were at distances $8 \mathrm{~mm}$ from the superior border of the $A C$ and $15 \mathrm{~mm}$ from the IBM. The MF was found at the AC in 25\% (9/36 cases), usually bilaterally (Fig. 3). In a unique mandible, the MF was detected on the AC, unilaterally. In dentate mandibles, the MF was found nearby the superior border of the $A C$, at an average distance $13.6 \mathrm{~mm}$, in $56.8 \%$ of the cases. The average distance of the MF from the IBM was $15.2 \mathrm{~mm}$. A decrease of $7.2 \mathrm{~mm}$ and $2.6 \mathrm{~mm}$ were observed as regards the distances MF-AC and MF-IBM between dentate and edentulous mandibles. The $t$-test was conducted for comparisons of the corresponding measurement between dentate and edentulous groups and distances at the edentulous group were statistically significantly lower at the 0.01 level. The lower values of distances in edentulous mandibles indicate the bone resorption on AC and IBM. A positive linear correlation

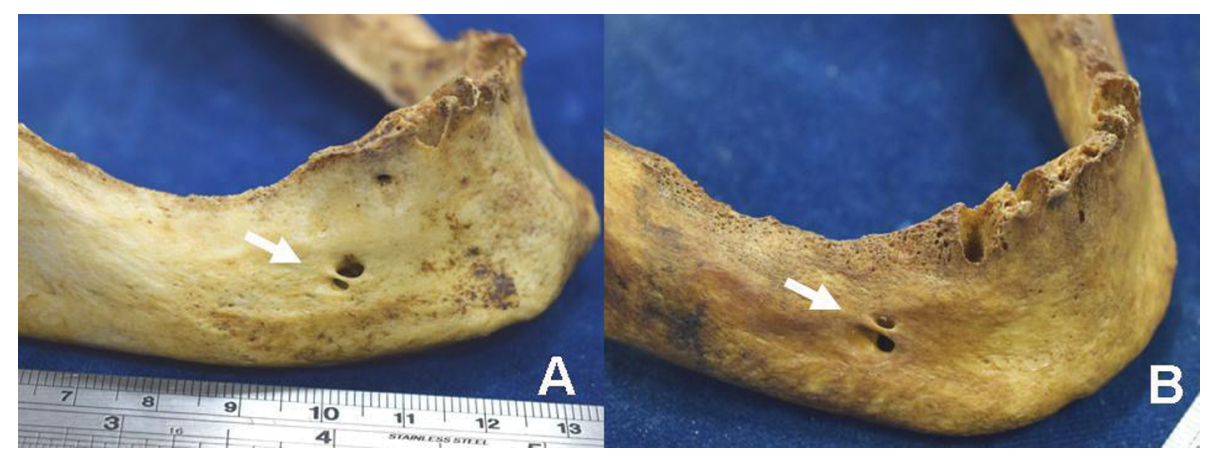

Figures 2. A, B. The white arrow indicates the septation at the external aperture of the mental foramen at the right side of both mandibles. 
between the symphyseal height and the MF-AC distance was detected in both groups. The correlations between the symphyseal height and MF-AC distance are stronger compared with MF-IBM, in both groups. No difference was observed between left and right sides $(p=0.39)$.

\section{DISCUSSION}

A wide variability exists concerning the MF location and morphology among several studies [28, 29]. Our study revealed an incidence of $5.6 \%$ of a double MF, a very near finding to Paraskevas et al. [22] results also performed in a Greek population. The MF duplication is explained taking into consideration the MN separation into several fasciculi earlier than MF formation up to the $12^{\text {th }}$ gestational week [22].

Agthong et al. [1] and Neiva et al. [20] found the MF at a distance $15 \mathrm{~mm}$ and $12 \mathrm{~mm}$ from the IBM, while the classic anatomical textbooks describe the MF position closer to the IBM, concerning the skulls of juveniles [31]. Our study concluded that the MF is located at an average distance $15.2 \mathrm{~mm}$ and $12.6 \mathrm{~mm}$ from the IBM in dentate and edentulous mandibles, respectively. Considering the mean values for the distance MF-IBM in dentate mandibles, the results of the present study in Greeks were similar to that observed for Africans, Chinese and Thais $[3,33]$ and higher than that related for British, Koreans and Americans [7, 8]. The studies of Güler et al. [13], Apinhasmit et al. [3] and Amorim et al. [2] reported a gender dimorphism, as the male mandibles of their sample presented higher values of MF-IBM distances than the female. Our study could not examine the gender effect on the MF location due to the unknown gender in our sample.

Mraiwa et al. [18] mentioned that the MF was usually located at a half distance between the $\mathrm{AC}$ and the IBM, in dentate mandibles. After teeth loss, the alveolar bone resorption transposes the MF closer to the AC [36] and in extreme situations, the foramen may be found on the crest of the alveolar ridge [5]. The current investigation reveals that the MF position is affected by the AC height and in mandibles with low values of heights the foramina are transposed very close to the AC.

After teeth loss, the alveolar bone is affected by a continuous bone resorption. The morphology of the mandible and the consequent resorption (bone remodelling process) are correlated with the gender and the age of the individual, the muscle forces, the face biotype, the teeth size, the status of edentulism, the oral parafunctions, the occlusion, the denture quality, the shape and size of neurocranium, the diet habits, the head position, the general health (use of medications, systemic diseases and osteoporosis), the environmental influences, several socioeconomic factors, the ethnic characteristics [40] and the racial miscegenation $[6,26]$. The degree of resorption is significant higher in mandibles of postmenopausal women with osteoporosis compared to these of healthy older women [41]. The severity of bone loss is highly associated with osteoporosis [38] and the ageing [15]. A female predisposition is mentioned [27]. The period of edentulism is also related to the alveolar ridge resorption and the status of edentulism (i.e. the total form) may lead to an early implant failure. Patients with long periods of edentulism often lose more mandibular bone than those with a shorter period [11, 12].

During several surgical procedures, such as genioplasty, mandibular rehabilitation after trauma, root resection of mandibular premolars, dental implants placement and orthognathic procedures, oral and maxillofacial surgeon should be aware of the possibility to encounter an atypically placed MF in the mental area in order to prevent the MN and adjacent blood vessels damage and the resulting postoperative paraesthesia, hypoesthesia, hyperaesthesia, dysaesthesia, or anaesthesia of the teeth, the lower lip, or surrounding skin and mucosa $[11,22,35]$. The resulting oedema after such compression $[24,30]$ or the haematoma formation (intraneural blood vessels trauma) [32] may also lead to a prolonged and possibly permanent change in sensation. Haemorrhage from the epineurial blood vessels would produce constrictive epineuritis, due to the reactive fibrosis and scar formation. Depending on the amount of pressure exercised on the $\mathrm{MN}$, the neural injury could be classified as neurapraxia ( $1^{\text {st }}$ degree injury) or as axonotmesis ( $2^{\text {nd }}$ degree injury) [32]. The incidence of sensory alterations is variable among the clinical studies due to the different locations of osteotomy, the modus of surgery, the study design and the sensitivity of evaluated techniques, the selection of outcome variables, and the terminology used to explain sensory disturbances. Dahlin et al. [9] also reported that compression on the nerves for 2 hours showed demyelination and axonal degeneration 3 weeks after compression. Concerning the MF location, after the radiographic estimation of the close proximity of the $\mathrm{MF}$ to the $\mathrm{AC}$, some authors propose the MF transpo- 
sition $[4,17]$ in order to avoid MN injury, when perform dental implants placement or osteotomies [25]. Other authors contradict, highlighting a high rate of sensory dysfunction postoperatively [10, 14, 21].

The current study had two limitations: the unknown gender and the age of dry mandibles.

\section{CONCLUSIONS}

The MF is a symmetric structure in Greeks. It is an important landmark and its location needs to be considered prior to any intervention at the anterior mandibular area in order to avoid the MN injury and related complications. The position of the foramen is altered in edentulous mandibles compared with the dentate ones. Thus, the MF location is directly affected by dental status. Evaluation of the status of the alveolar ridge in edentulous mandibles is very important during the process of construction of removable dentures and dental implants placement. The morphology of edentulous mandibles increases the risk of intraoperative complications at the anterior mandible.

\section{REFERENCES}

1. Agthong S, Huanmanop T, Chentanez V. Anatomical variations of the supraorbital, infraorbital, and mental foramina related to gender and side. J Oral Maxillofac Surg. 2005; 63(6): 800-804, doi: 10.1016/j.joms.2005.02.016, indexed in Pubmed: 15944977.

2. Amorim MM, Prado FB, Borini CB, et al. The mental foramen position in dentate and edentulous brazilian's mandible. Int J Morphol. 2008; 26(4): 981-987, doi: 10.4067/ s0717-95022008000400033.

3. Apinhasmit W, Chompoopong S, Methathrathip D, et al. Supraorbital notch/foramen, infraorbital foramen and mental foramen in thais: anthropometric measurements and surgical relevance. J Med Assoc Thai. 2006; 89(5): 675-682, indexed in Pubmed: 16756055.

4. Babbush C. Transpositioning and repositioning the inferior alveolar and mental nerves in conjunction with endosteal implant reconstruction. Periodontology 2000. 1998; 17(1): 183-190, doi: 10.1111/j.1600-0757.1998.tb00134.x.

5. Block MS. Color Atlas of Dental Implant Surgery. WB Saunders, Philadelphia 2001.

6. Bogin B, Rios L. Rapid morphological change in living humans: implications for modern human origins. Comp Biochem Physiol A Mol Integr Physiol. 2003; 136(1): 71-84, indexed in Pubmed: 14527631.

7. Chung MS, Kim HJ, Kang HS, et al. Locational relationship of the supraorbital notch or foramen and infraorbital and mental foramina in Koreans. Acta Anat (Basel). 1995; 154(2): 162-166, indexed in Pubmed: 8722516.

8. Cutright B, Quillopa N, Schubert W. An anthropometric analysis of the key foramina for maxillofacial surgery. J Oral Maxillofac Surg. 2003; 61 (3): 354-357, doi: 10.1053/ joms.2003.50070, indexed in Pubmed: 12618976.
9. Dahlin LB, Danielsen N, Ehira T, et al. Mechanical effects of compression of peripheral nerves. J Biomech Eng. 1986; 108(2): 120-122, indexed in Pubmed: 3724098.

10. Ellies LG, Smiler DG, Quadland MW, et al. Inferior alveolar nerve repositioning: is there cause for concern? Dent Implantol Update. 1995; 6(4): 32-37, indexed in Pubmed: 9525143.

11. Greenstein G, Tarnow D. The mental foramen and nerve: clinical and anatomical factors related to dental implant placement: a literature review. J Periodontol. 2006; 77(12): 1933-1943, doi: 10.1902/jop.2006.060197, indexed in Pubmed: 17209776.

12. Grisar K, Sinha D, Schoenaers J, et al. Retrospective analysis of dental implants placed between 2012 and 2014: indications, risk factors, and early survival. Int J Oral Maxillofac Implants. 2017; 32(3): 649-654, doi: 10.11607/jomi.5332, indexed in Pubmed: 28212455.

13. Güler $A U$, Sumer $M$, Sumer $P$, et al. The evaluation of vertical heights of maxillary and mandibular bones and the location of anatomic landmarks in panoramic radiographs of edentulous patients for implant dentistry. J Oral Rehabil. 2005; 32(10): 741-746, doi: 10.1111/j.1365-2842.2005.01499.x, indexed in Pubmed: 16159352.

14. Hori M, Sato T, Kaneko K, et al. Neurosensory function and implant survival rate following implant placement with nerve transpositioning: a case study. J Oral Sci. 2001; 43(2): 139-144, indexed in Pubmed: 11515599.

15. Jagadeesh D, Patil RA, Kattimani PT. Clinical evaluation of mandibular ridge height in relation to aging and length of edentulism. J Dental Med Scien. 2013; 3(4): 44-47, doi: 10.9790/0853-0344447.

16. Kovačić I, Knezović Zlatarić D, Celebić A. Residual ridge atrophy in complete denture wearers and relationship with densitometric values of a cervical spine: a hierarchical regression analysis. Gerodontology. 2012; 29(2): e935e947, doi: 10.1111/j.1741-2358.2011.00589.x, indexed in Pubmed:22098144.

17. Morrison A, Chiarot M, Kirby S. Mental nerve function after inferior alveolar nerve transposition for placement of dental implants. J Can Dent Assoc. 2002; 68(1): 46-50, indexed in Pubmed: 11844418.

18. Mraiwa N, Jacobs $R$, van Steenberghe $D$, et al. Clinical assessment and surgical implications of anatomic challenges in the anterior mandible. Clin Implant Dent Relat Res. 2003; 5(4): 219-225, indexed in Pubmed: 15127992.

19. Natsis K, Repousi E, Asouhidou I, et al. Foramina of the anterior mandible in dentate and edentulous mandibles. Folia Morphol. 2016; 75(2): 204-210, doi: 10.5603/ FM.a2015.0090, indexed in Pubmed: 26431051.

20. Neiva RF, Gapski R, Wang HL. Morphometric analysis of implant-related anatomy in Caucasian skulls. J Periodontol. 2004; 75(8): 1061-1067, doi:10.1902/jop.2004.75.8.1061, indexed in Pubmed: 15455732.

21. Nocini PF, De Santis D, Fracasso E, et al. Clinical and electrophysiological assessment of inferior alveolar nerve function after lateral nerve transposition. Clin Oral Implants Res. 1999; 10(2): 120-130, indexed in Pubmed: 10219131.

22. Paraskevas G, Mavrodi A, Natsis K. Accessory mental foramen: an anatomical study on dry mandibles and review of the literature. Oral Maxillofac Surg. 2015; 19(2): 
177-181, doi: 10.1007/s10006-014-0474-1, indexed in Pubmed: 25394607.

23. Phillips JL, Weller RN, Kulild JC. The mental foramen: 1. Size, orientation, and positional relationship to the mandibular second premolar. J Endod. 1990; 16(5): 221-223, indexed in Pubmed: 2074415.

24. Pogrel MA, Thamby S. Permanent nerve involvement resulting from inferior alveolar nerve blocks. J Am Dent Assoc. 2000; 131(7): 901-907, indexed in Pubmed: 10916328.

25. Politis C, Sun Y, Lambrichts I, et al. Self-reported hypoesthesia of the lower lip after sagittal split osteotomy. Int J Oral Maxillofac Surg. 2013; 42(7): 823-829, doi: 10.1016/j. ijom.2013.03.020, indexed in Pubmed: 23639585.

26. Prado F, Caria P. Comparaciones morfológicas entre las mandíbulas de brasileños y de poblaciones de otros continentes. Int J Morphol. 2007; 25(2): 323-327, doi: 10.4067/ s0717-95022007000200013.

27. Şakar O, Sülün T, İspirgil E. Correlation of the gonial angle size with residual ridge resorption in edentulous subjects. Balkan J Stomatol. 2008; 12: 38-41.

28. Sawyer DR, Kiely ML, Pyle MA. The frequency of accessory mental foramina in four ethnic groups. Arch Oral Biol. 1998; 43(5): 417-420, indexed in Pubmed: 9681117.

29. Shankland WE. The position of the mental foramen in Asian Indians. J Oral Implantol. 1994; 20(2): 118-123, indexed in Pubmed: 7869414.

30. Sharawy M, Misch CE. Anatomy for dental implants. In: Misch CE, ed. Contemporary Implant Dentistry. 2nd Ed. The CV Mosby Company, St. Louis 1999: 217-224.

31. Sicher H, Du Br. Oral anatomy, 5th Ed. CV Mosby Co, St. Louis 1970: 502.

32. Smith MH, Lung KE. Nerve injuries after dental injection: a review of the literature. J Can Dent Assoc. 2006; 72(6): 559-564, indexed in Pubmed:16884649.

33. Souaga K, Adou A, Angoh Y. [Topographical and morphological study of the mandibular foramen in black
Africans from the Ivory Coast]. Odontostomatol Trop. 2004; 27(105): 17-21, indexed in Pubmed: 15281297.

34. Tallgren A. The continuing reduction of the residual alveolar ridges in complete denture wearers: a mixedlongitudinal study covering 25 years. J Prosthetic Dentistry. 2003; 89(5): 427-435, doi: 10.1016/s00223913(03)00158-6.

35. Toh H, Kodama J, Yanagisako M, et al. Anatomical study of the accessory mental foramen and the distribution of its nerve. Okajimas Folia Anat Jpn. 1992; 69(2-3): 85-88, indexed in Pubmed: 1436953.

36. Ulm CW, Solar P, Blahout R, et al. Location of the mandibular canal within the atrophic mandible. Br J Oral Maxillofac Surg. 1993; 31 (6): 370-375, indexed in Pubmed: 8286291.

37. Van Waas MA, Jonkman RE, Kalk W, et al. Differences two years after tooth extraction in mandibular bone reduction in patients treated with immediate overdentures or with immediate complete dentures. J Dent Res. 1993; 72(6): 1001-1004, doi: 10.1177/00220345930720060101, indexed in Pubmed: 8496472.

38. Watanabe $\mathrm{P}$, Issa J, Oliveira $\mathrm{T}$, et al. Morphodigital Study of the Mandibular Trabecular Bone in Panoramic Radiographs. Int J Morphol. 2007; 25(4): 875-880, doi: 10.4067/ s0717-95022007000400031.

39. Wismeijer D, van Waas MA, Vermeeren Jl, et al. Patients' perception of sensory disturbances of the mental nerve before and after implant surgery: a prospective study of 110 patients. Br J Oral Maxillofac Surg. 1997; 35(4): 254-259, indexed in Pubmed: 9291263.

40. Yeşilyurt $H$, Aydinlioglu A, Kavakli A, et al. Local differences in the position of the mental foramen. Folia Morphol. 2008; 67(1): 32-35, indexed in Pubmed: 18335411.

41. Zmysłowska E, Ledzion S, Jedrzejewski K. Factors affecting mandibular residual ridge resorption in edentulous patients: a preliminary report. Folia Morphol. 2007; 66(4): 346-352, indexed in Pubmed: 18058759. 